\title{
Comparison of radial artery patency according to proximal anastomosis site: Direct aorta to radial artery anastomosis is superior to radial artery composite grafting
}

\author{
Sung-Ho Jung, MD, ${ }^{a}$ Hyun Song, MD, ${ }^{\text {a }}$ Suk Jung Choo, MD, ${ }^{\text {a Hyung Gon Je, MD, }}{ }^{\text {a }}$ \\ Cheol Hyun Chung, MD, ${ }^{a}$ Joon-Won Kang, MD, ${ }^{b}$ and Jae Won Lee, MD $^{\mathrm{a}}$
}

\begin{abstract}
Objective: The radial artery is frequently the second graft of choice after the left internal thoracic artery in coronary artery bypass graft surgery. However, the optimal radial artery proximal anastomosis site remains controversial. The aim of the present study was to compare the radial artery patency according to its use as either an aorta-radial artery graft or composite radial artery graft in coronary artery bypass grafting.
\end{abstract}

\begin{abstract}
Methods: A total of 1735 patients received coronary artery bypass grafting using the radial artery between January 2001 and July 2007, of whom 893 received serial computed tomographic coronary angiographies; these patients formed the basis of the current study. The patients were divided into 2 groups: group I (direct radial artery to aortic anastomosis, $\mathrm{n}=451$ patients) and group II (radial artery composite grafting with the left internal thoracic artery, $\mathrm{n}=442$ patients). The number of distal radial artery anastomoses performed in group I was 657 and 749 in group II. Sequential bypassing was performed in 399 patients.
\end{abstract}

Results: The early patency rate was significantly higher in group I than in group II $(98.3 \%$ vs $94.5 \% ; P=.004)$. The 1-, 2-, and 5-year patency rates were also higher in group I than in group II $(93.8 \% \pm 1.2 \%, 90.5 \% \pm 1.6 \%$, and $74.3 \% \pm 6.1 \%$, vs $90.5 \% \pm 1.4 \%, 85.3 \% \pm 1.9 \%$, and $65.2 \% \pm 4.2 \%$, respectively; $P=.004)$. Multivariate analysis showed composite grafting $(P=.02)$, the degree of target vessel stenosis $<90 \%(P=.001)$, and the target revascularization site $(P=.005)$ to be significant risk factors for occlusion.

Conclusion: The results of the current data showed superior early and late patency rates of coronary artery bypass grafting with radial artery to aorta anastomosis compared with left internal thoracic artery-radial artery composite grafting.

Left anterior descending (LAD) coronary artery bypass grafting $(\mathrm{CABG})$ with the left internal thoracic artery (LITA) is regarded as the gold standard in coronary bypass surgery. ${ }^{1}$ To overcome the purported higher failure rates of saphenous vein grafts (SVGs), surgery with all arterial grafts has been advocated whenever possible. The radial artery (RA), which was used for the first time by Carpentier and colleagues $^{2}$ in 1971 , was initially met with disappointing results, but with various methods to counter spasm such as en bloc harvesting, the long-term outcome has improved significantly, with the RA currently being used as the second graft of choice after the LITA in many institutions. ${ }^{3-5}$ However, controversies regarding the optimal site of the proximal

From the Department of Thoracic and Cardiovascular Surgery, ${ }^{\text {a }}$ and Department of Radiology, ${ }^{\mathrm{b}}$ Asan Medical Center, College of Medicine, University of Ulsan, Seoul, Republic of Korea.

This study was supported by grants from the Asan Institute for Life Science, Seoul, Republic of Korea.

Received for publication Aug 8, 2008; revisions received Nov 14, 2008; accepted for publication Dec 6, 2008.

Address for reprints: Hyun Song, MD, PhD, Department of Thoracic and Cardiovascular Surgery, Asan Medical Center, 388-1 Poongnap-Dong, Songpa-Ku, Seoul,

Republic of Korea, 138-736 (E-mail: hyunsong@amc.seoul.kr).

J Thorac Cardiovasc Surg 2009;138:76-83

$0022-5223 / \$ 36.00$

Copyright (c) 2009 by The American Association for Thoracic Surgery

doi: $10.1016 /$ j.jtcvs.2008.12.004
RA anastomosis remain ${ }^{6,7}$ because of prevailing arguments supporting either direct anastomosis to the aorta or composite grafting, namely, with the LITA. In previous studies, the radial proximal anastomosis site was reported to be inconsequential in affecting long-term patency as opposed to the degree of target vessel stenosis and target territory bypassed. ${ }^{5,8-10}$ Efforts to economize on the limited arterial graft length and to achieve all arterial off-pump coronary artery bypass surgery (OPCAB) have led to the increased use of the RA as a composite bypass graft. However, we hypothesize that direct aortic anastomosis yields superior results to the LITA-RA composite graft because of the higher drive pressure and flow afforded by the direct aortic connection. The aim of the current study was to assess the implications of the proximal anastomosis site on the patency of RA grafts in CABG. Follow-up assessments were made with multidetector computed tomographic (MDCT) coronary angiograms.

\section{MATERIALS AND METHODS}

A total of 2791 patients underwent CABG at Asan Medical Center between January 2001 and July 2007. Of these patients, RA grafts were used in 1735 patients. The RA graft was the second arterial conduit of choice after the LITA, except in patients with chronic renal failure. Patients receiving concomitant procedures for valve disease, left ventricular reconstruction, ascending aortic disease, or surgery for other congenital heart 


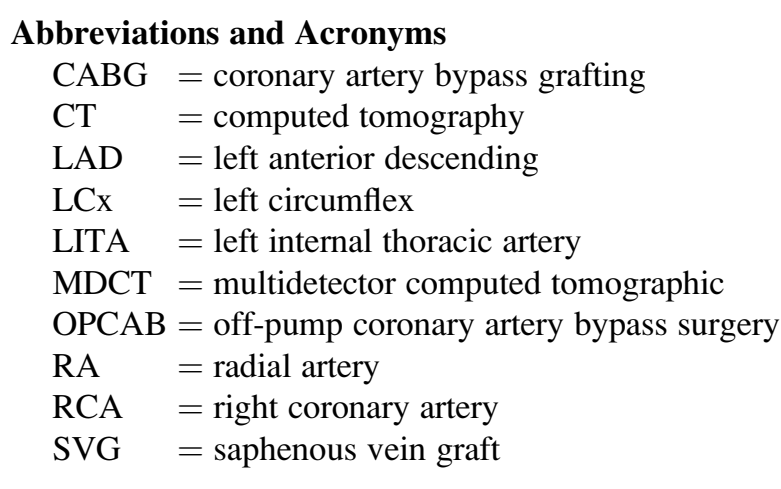

disease were excluded. Patients with 2 proximal anastomoses $(n=33$, ie, aorta and LITA) were also excluded to obtain a uniform study group. Patients receiving epicardial maze procedures, redo operations, and minimally invasive direct coronary artery bypass procedures, however, were not excluded from the current study. A total of 1543 patients (576 in group I and 967 in group II) were identified as meeting the study inclusion criteria. Three other patients were also excluded because of poor computed tomography (CT) image quality resulting from arrhythmia, lung atelectasis, and severe obesity. The current study population was based on the remaining 893 patients in whom serial postoperative CT coronary angiograms were performed. The study protocol was approved by the institutional review board of Asan Medical Center, Seoul, Korea. The requirement for informed patient consent was waived by the institutional review board because of the retrospective nature of the current study.

Direct RA to aorta anastomosis was performed in 451 patients (group I; aorta-RA) and LITA composite grafting in 442 patients (group II; composite graft). The number of RA distal anastomoses was 657 in group I and 749 in group II. The target territories were categorized as the LAD artery (LAD, diagonal branch), the left circumflex (LCx) artery (obtuse marginal branch, ramus intermedius), and the right coronary artery (RCA) territories (distal RCA, posterior descending artery, posterolateral branch). The degree of target vessel stenosis was described as less than or greater than $90 \%$.

The type of proximal anastomosis (aorta-RA or composite graft) was determined by the distribution of coronary artery disease, the state of an ascending aortic disease, the graft length, and the surgeon's preference.

\section{Surgical Techniques}

Surgery was conducted by 1 of 5 adult cardiac surgeons. The surgeons varied in their operative techniques regarding the mode of RA proximal anastomosis (ie, aortic anastomosis under cardioplegic arrest vs anastomosis after aortic side clamping), the use of the pump (ie, conventional vs OP$\mathrm{CAB}$ ), and the mode of bypass (ie, sequential vs individual grafting). All surgeons had a minimum surgical experience of more than 500 coronary artery bypass procedures before the study. The left RA was harvested in righthanded individuals, and vice versa, whenever possible. A modified Allen test, which was routinely performed preoperatively, was complemented by oxygen saturation assessment in the RA territory using a digital oximeter thumb probe. Failure of a normal tracing to reappear with the ulnar artery reopening after bilateral forearm artery compression-induced obliteration of the normal oxygen saturation curve was considered as a state of inadequate collateral circulation. In most cases, the RA was dissected en bloc as a vascular pedicle together with the satellite veins using a harmonic scalpel. Harvesting from the forearm was done only after adequate systemic heparinization was achieved. The distal RA coronary anastomoses were performed with continuous 8-0 polypropylene sutures. The Y-or T-graft anastomoses between the RA and the LITA were performed with continuous 7-0 polypropylene sutures either to the pleural or thoracic aspect of the LITA, where its course was noted to enter the pericardial space anterior to the left atrial appendage. The RA aortic anastomosis was performed with continuous 6-0 or 7-0 polypropylene sutures after creating a 3.5-mm circular (single-use aorta/vein punches, Scanlan International, St Paul, Minn) punch defect.

\section{Antispasm Protocols}

Radial artery spasm immediately after harvesting was treated with gentle papaverine topical application and intraluminal flushing. As a further measure, calcium channel blockade was performed with continuous intravenous administration of diltiazem at a dosage of $1 \mu \mathrm{g} / \mathrm{kg} / \mathrm{min}$ in the operating theater and intensive care unit. Diltiazem was continued orally for at least 6 months postoperatively.

\section{Other Postoperative Medication}

For platelet inhibition, aspirin $100 \mathrm{mg}$ and clopidogrel $75 \mathrm{mg}$ (during 6 months) were administered daily as soon as patients were extubated. Anticoagulation with heparin or warfarin was not performed routinely but only in the presence of atrial fibrillation or after coronary endarterectomy.

\section{Follow-up Coronary Computed Tomographic Angiography}

Coronary CT angiogram was performed with a 16-channel MDCT (Somatom Sensation 16, Siemens Medical Solutions, Forchheim, Germany) before November 2006 and then replaced with a dual-source CT (Somatom Definition, Siemens Medical Solutions) thereafter. The latter machine, which is an upgraded version of the 64-channel MDCT, has a superior time resolution by a factor of 2 . Patients were routinely scheduled for follow-up coronary CT angiography 1 week postoperatively before discharge. In the presence of nonoliguric renal dysfunction or failure defined as a creatinine level more than $1.4 \mathrm{~g} / \mathrm{dL}$, coronary CT angiograms were performed after preprocedural $\mathrm{N}$-acetylcysteine medication and appropriate hydration in consenting patients only. However, in patients with normal renal function, routine follow-up coronary $\mathrm{CT}$ angiograms were performed at 6 months postoperatively, 1 year later, and every 2 years thereafter, whenever possible. In the event of a new-onset angina, however, coronary CT angiogram was performed immediately.

The status of graft patency was divided into 1 of 3 descriptive imaging categories; patent, faint (ie, visualization but some stenosis or spasm), or nonvisualized (ie, total occlusion). In sequential bypass grafts showing nonvisualization from inflow site to the side-to-side anastomosis while showing patency beyond the side-to-side anastomosis, we assessed the proximal portion to be occluded while maintaining that the distal portion to be patent. All coronary CT angiograms were reviewed by a single experienced radiologist.

\section{Data Analysis}

Data are expressed as mean \pm standard deviation for continuous variables and as numbers with percentages for categoric variables. Paired and unpaired Student $t$ tests were used to determine intra- and intergroup differences between mean values for continuous variables, as appropriate. Patency rates were estimated using the Kaplan-Meier method, and intergroup comparison was performed using log-rank tests. Cox-regression analysis and the Cox proportional hazard model were used for graft occlusion risk factor analysis. Statistical Package for the Social Sciences software 14.0 (Korean version; SPSS, Inc, Chicago, Ill) was used for statistical analysis.

\section{RESULTS}

Data of a total of 1543 patients who met the inclusion criteria were as follows. The mean age was $61.5 \pm 0.5$ years in group I and $61.9 \pm 8.4$ years in group II $(P=.39)$. OPCAB 
was performed in $26 \%$ of patients $(150 / 576)$ in group I and $42.6 \%$ of patients $(412 / 967)$ in group II $(P<.0001)$. The mean number of grafts $(3.3 \pm 0.9$ in group I vs $3.7 \pm 1.0$ in group II, $P<.0001$ ) and the number of arterial grafts $(2.6 \pm 0.8$ in group I vs $3.1 \pm 0.9$ in group II, $P<.0001)$ were greater in group II. Early mortality was $0.8 \%$ for the entire cohort (5/576 in group I vs 8/967 in group II, $P=$ .932) and the incidence of postoperative complications, such as stroke and need for intraaortic balloon pump insertion, were $0.9 \%$ (4/576 in group I vs $10 / 967$ in group II, $P=.588)$ and $1.6 \%$ (11/576 in group I vs $13 / 967$ in group II, $P=.385)$.

\section{Study Populations}

The patients in both groups showed similar preoperative demographics (ie, age, serum creatinine levels, similar incidence of diabetes mellitus, systemic hypertension, and preoperative intraaortic balloon pump insertion). However, there were more men, OPCAB surgeries, and sequential bypassing in group II than in group I. The left ventricular function in group I was slightly better than in group II. The total number of grafts and arterial grafts used were higher in group II than in group I. However, both groups had a similar degree of target vessel stenosis and target territories supplied with the RA. By site, the LCx territory was the most frequently bypassed with the RA (Table 1).

\section{Early and Late Graft Patency}

Early postoperative coronary CT angiograms were performed in 1044 distal RA anastomoses (531 in group I and 513 in group II). The RA was nonvisualized in $1.7 \%$ (7/ $531)$ of group I patients and $5.5 \%$ (25/513) of group II patients $(P=.004)$, and a similar proportion of RA grafts in the 2 groups were classified as being "faint" (Table 2). Thus, the overall early patency rate was superior in group I compared with group II. The RA graft patency rates for the entire cohort were $92.2 \% \pm 0.9 \%, 87.9 \% \pm 1.2 \%$, and $69.1 \% \pm 3.5 \%$ at 1,2 , and 5 years, respectively, and when stratified by the study groups they were $93.8 \% \pm 1.2 \%$, $90.5 \% \pm 1.6 \%$, and $74.3 \% \pm 6.1 \%$, respectively, in group I and $90.5 \% \pm 1.4 \%, 85.3 \% \pm 1.9 \%$ and $65.2 \% \pm 4.2 \%$, respectively, in group II ( $P=.004$, Figure 1).

Nonvisualization was regarded as occlusion. In group I, however, 2 of 7 occluded grafts became patent later, and in group II, 5 of 25 occluded grafts showed such changes on serial CT coronary angiography. These patients were later added to the group of patients assessed as having patent grafts.

\section{Risk Factors for Graft Occlusion}

Analyses of risk factors for graft occlusion were performed on patient demographics, preoperative cardiac function, target vessel stenosis, bypassed territory, mode of surgery, and technique used (eg, site of proximal anastomo- sis, OPCAB vs conventional CABG vs on-pump beating heart surgery, sequential vs individual anastomosis). Univariate analysis showed $\mathrm{OPCAB}(P=.021)$ to be a significant risk factor for occlusion with superior results being noted in group I patients compared with group II patients (Figure 2). Composite grafting $(P=.005)$, the degree of target vessel stenosis less than $90 \%(P=.001)$, and the target territory bypassed (LCx territory $[P=.004]$ and RCA territory $[P=.004])$ also were significant risk factors for occlusion (Figure 3, $A$ and $B$ ). Sequential bypassing, however, was not $(P=.494)$. Multivariate analysis showed composite grafting, degree of target vessel stenosis less than $90 \%$, and target territory bypassed to be significant risk factors for graft occlusion (Table 3) but not OPCAB.

\section{DISCUSSION}

Studies indicate LITA anastomosis to the LAD coronary artery correlates best with survival benefit and long-term patency. ${ }^{1}$ Although the SVG has traditionally been the second graft of choice, studies have consistently reported inferior long-term results of vein grafts relative to the LITA conduit. ${ }^{11}$ As an alternative to the LITA, a recent report by Collins and colleagues ${ }^{12}$ indicated superior patency with the RA grafts compared with the SVGs at the 5-year angiographic follow-up. However, to date, the evidence is scant for resolving the issue of which graft conduit is superior. ${ }^{13}$ By leaving the relative merits aside, the use of the RA has several advantages, including the ease and rapidity of harvesting, ability to secure suitable conduit length for bypassing almost any coronary artery territory, potentially superior adaptability to high arterial pressures, calibers that match most coronary arteries, and ease of handling because of the relatively thicker nature of the muscular arterial wall. ${ }^{14}$ In the seminal study by Carpentier and colleagues ${ }^{2}$ in which the RA was anastomosed to the aorta (ie, aorta-RA), the angiographic studies showed excellent outcomes. ${ }^{3,4}$ However, Calafiore and colleagues ${ }^{6}$ have argued that RA grafts anastomosed directly to the ascending aorta may be particularly susceptible to developing fibrous intimal hyperplasia because of the direct effects of the high aortic wall stress. By the same logic, LITA composite grafting may be expected to result in reduced RA wall stress by avoiding direct exposure of the central arterial pressure. Contrasting study results, however, have shown the site of the proximal anastomosis to not have any significant influence on either the early or late patency rates; ${ }^{5,8,10,15}$ instead, the patency of RA grafts was reported to be more closely related to the target territory bypassed and the degree of target vessel stenosis. ${ }^{7,9}$ In the current study, it was hypothesized that the influence of direct RA aortic anastomosis would not only be well tolerated but also exert a positive influence through the higher aortic drive pressure. The RA is by nature a systemic arterial conduit, and therefore most likely to be well suited to withstand the rigid mechanical conditions of the arterial environment 
TABLE 1. Preoperative demographic and clinical data

\begin{tabular}{|c|c|c|c|}
\hline & $\begin{array}{c}\text { Group I } \\
(n=451)\end{array}$ & $\begin{array}{l}\text { Group II } \\
(n=442)\end{array}$ & $\begin{array}{c}P \\
\text { value }\end{array}$ \\
\hline Age (y) & $61.7 \pm 8.3$ & $61.9 \pm 8.5$ & .618 \\
\hline Sex (male, \%) & $318(71 \%)$ & $348(79 \%)$ & .006 \\
\hline Diabetes mellitus & $153(34 \%)$ & $148(34 \%)$ & .887 \\
\hline Systemic hypertension & $236(53 \%)$ & $214(49 \%)$ & .127 \\
\hline Ejection fraction $(\%)$ & $57.5 \pm 10.0$ & $55.4 \pm 11.4$ & .003 \\
\hline$\leq 35 \%$ & $4.8 \%(21 / 442)$ & $6.7 \%(29 / 436)$ & .224 \\
\hline Total graft & $3.4 \pm 0.9$ & $3.6 \pm 1.0$ & $<.001$ \\
\hline Arterial graft & $2.6 \pm 0.8$ & $2.9 \pm 0.9$ & $<.001$ \\
\hline OPCAB & $126(28 \%)$ & $211(48 \%)$ & $<.001$ \\
\hline Sequential RA anastomosis & $139(31 \%)$ & $260(59 \%)$ & $<.001$ \\
\hline Preoperative IABP insertion & $16(4 \%)$ & $10(3 \%)$ & .431 \\
\hline Serum creatinine level & $1.0 \pm 0.6$ & $1.0 \pm 0.3$ & .737 \\
\hline No. of distal anastomoses & 660 & 750 & \\
\hline Target location & & & .401 \\
\hline LAD & $227(35 \%)$ & $233(31 \%)$ & \\
\hline $\mathrm{LCx}$ & $356(54 \%)$ & $428(57 \%)$ & \\
\hline RCA & $75(11 \%)$ & $87(12 \%)$ & \\
\hline Distal RCA & 13 & 4 & \\
\hline PDA or PL branch & 62 & 83 & \\
\hline Target stenosis & & & .264 \\
\hline$<90 \%$ & $245(51 \%)$ & $248(49 \%)$ & \\
\hline $90 \%-100 \%$ & $240(49 \%)$ & $239(51 \%)$ & \\
\hline
\end{tabular}

OPCAB, Off-pump coronary artery bypass surgery; IABP, intraaortic balloon pump; $L A D$, left anterior descending artery territory; $L C x$, Left circumflex artery territory; $R C A$, right coronary artery territory; $P D A$, posterior descending artery; $P L$, posterolateral; $R A$, radial artery.

and the direct flow of the aorta. Furthermore, the higher pressure and flow conditions afforded by the aorta-RA anastomosis may act favorably to overcome the forces of competition-induced RA occlusion, to which the RA is especially susceptible. ${ }^{9,10}$ Therefore, from this perspective, the RA-aortic anastomosis may provide a more advantageous hemodynamic environment over the weaker flow conditions of the LITA-RA composite graft. In keeping with these arguments, the early and late results of group I in the present study were superior to those of group II under similar conditions of preoperative demographics, degree of target vessel stenosis, and target territories bypassed.

To assess the influence of competitive flow, we compared the graft patency between the 2 groups using a proximal target stenosis of $90 \%$ or more as cutoff for defining critical stenosis (ie, $\geq 90$ or $<90 \%$ ). With $90 \%$ or more proximal stenosis, graft patency between the 2 groups was similar $(P=.286)$, but with target stenosis less than $90 \%$ the patency rate was better in group I compared with group II

TABLE 2. Early patency rates according to the anastomosis number

\begin{tabular}{lcccr}
\hline & Patent & Faint & Nonvisualization* & Total \\
\hline Group I & $482(90.6)$ & $42(7.6)$ & $7(1.7)$ & 531 \\
Group II & $450(87.4)$ & $38(7.1)$ & $25(5.5)$ & 513 \\
Total & $932(89.3)$ & $80(7.7)$ & $32(3.1)$ & 1044 \\
\hline
\end{tabular}

Numbers in parentheses represent percentages. ${ }^{*} P=.004$.

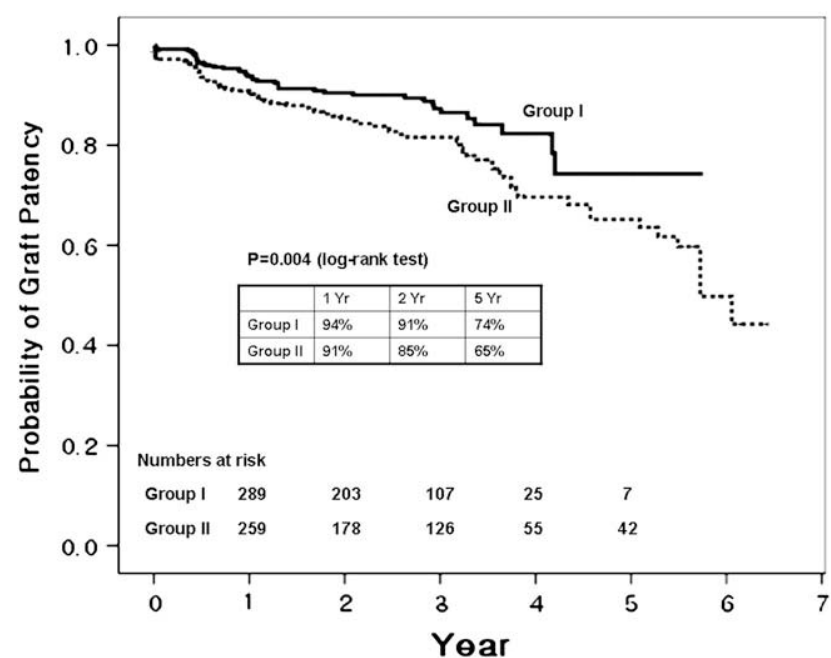

FIGURE 1. Comparison of patency rates between groups I and II using log-rank tests.

$(P=.047)$ (Figure 4). These results suggest the influence of flow competition on long-term RA graft patency.

There were more bypasses and arterial bypasses in group II than in group I. This may be attributed to the increased tendency to perform sequential bypassing with the LITA RA composite grafts. The use of the RA composite graft has been driven in part by the desire to achieve all arterial OP$\mathrm{CAB}$ with the "no touch technique." Although OPCAB per se was not found to be a significant risk factor for graft occlusion on multivariate analysis, the negative influence of composite grafting (Figure 2) was reflected in the relatively inferior graft patency in group II versus group I. Despite such potential disadvantages, the OPCAB LITA RA composite grafting is currently widely advocated for its stroke-reducing potential. In the current study, however, the necessity for aortic side clamping in the aorta-RA group did not result in a greater incidence of stroke or other related complications, as anticipated.

In regard to the influence of territory bypassed, previous studies reported the RCA territory to demonstrate the poorest results. ${ }^{8,9}$ RA bypassing to the RCA territory was also identified as a risk factor for graft occlusion in the current study. In RCA territory, the diameter of distal RCA is usually larger than that of PDA or posterolateral branch. Intergroup (group I vs group II) and intragroup (distal RCA vs PDA or posterolateral branch) comparisons of bypass graft patency according to bypassed sites along the RCA territory (ie, distal RCA, PDA, and posterolateral branch) showed no significant differences. These findings may be partially attributed to the small number of grafts bypassed, especially to the distal RCA of the RCA territory, to demonstrate any significant site-specific differences. Therefore, further studies with a larger patient cohort may be necessary for a more definitive difference. 

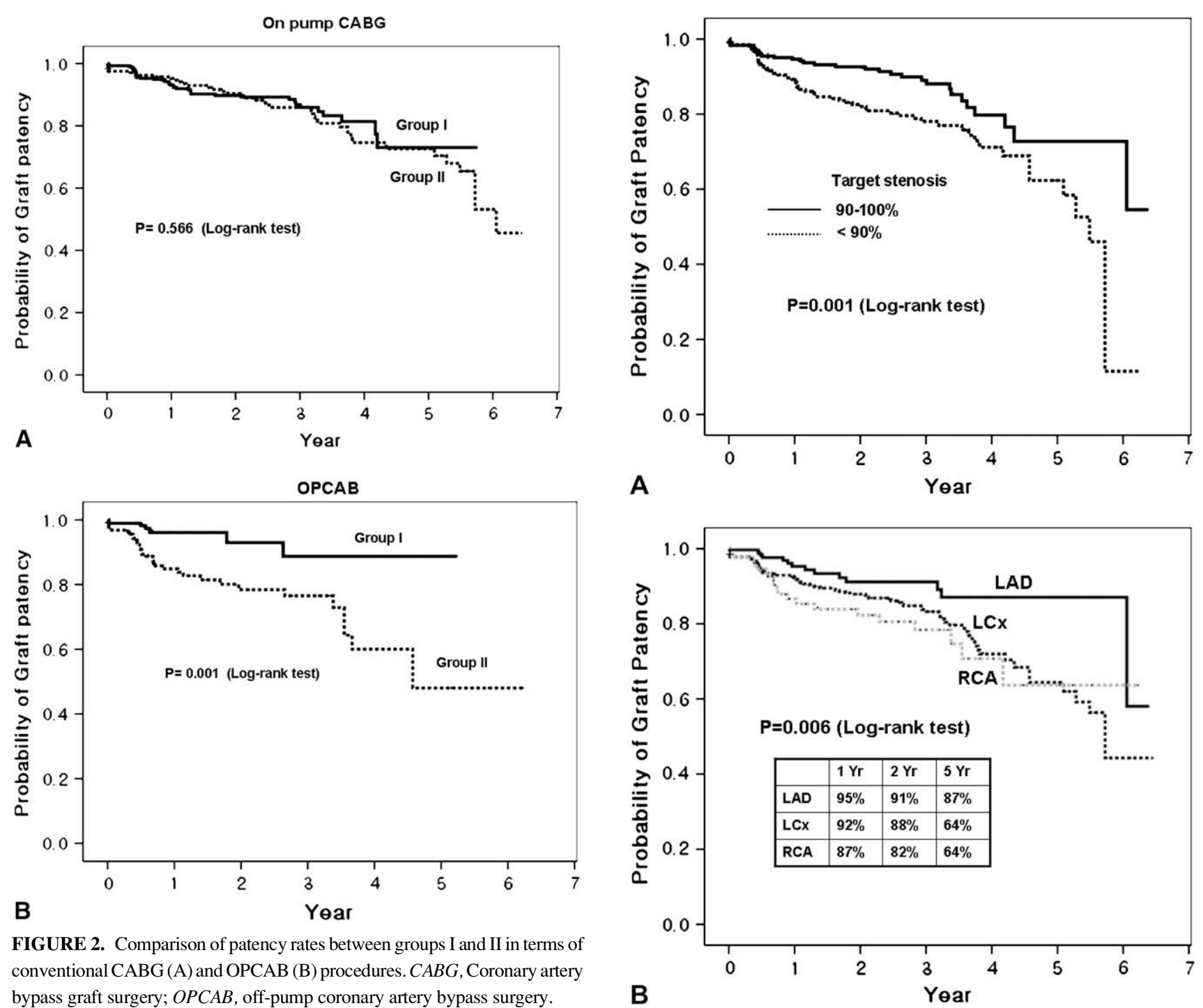

FIGURE 2. Comparison of patency rates between groups I and II in terms of conventional $\mathrm{CABG}(\mathrm{A})$ and $\mathrm{OPCAB}(\mathrm{B})$ procedures. $C A B G$, Coronary artery bypass graft surgery; $O P C A B$, off-pump coronary artery bypass surgery.

In addition, RA bypass to the LCx artery territory was associated with a significantly higher risk of graft occlusion compared with bypassing to the LAD territory (Figure 3, B). This may be due to differences in the distal runoff between the 2 bypass territories favoring the LAD because it is usually the larger vessel with more branches, that is, multiple septal perforators and diagonal branches resulting in coverage of a larger territory and a collectively lower vascular resistance. ${ }^{16}$

The target vessel diameter is an important factor affecting patency. We usually bypassed coronary arteries with the diameters equal to $1.5 \mathrm{~mm}$ or greater. In the present study, however, because the data on the target vessel diameter were incomplete and tended to be subjective, we did not investigate it as a risk factor for graft patency.

In the present study, the 1- and 5-year patency rates for all patients were $92 \%$ and $65 \%$, respectively. Although the 1 -year patency rate was comparable to that of other reports, the 5-year patency rate was apparently lower than the

FIGURE 3. Long-term patency rates according to the target stenosis (A) and target territory (B). $L A D$, Left anterior descending artery territory; $L C x$, left circumflex artery territory; $R C A$, right coronary artery territory.

reported $83 \%$ to $91 \%$ patency rate of other studies. ${ }^{3,4,17,18}$ This may be attributed in part to the disparities in the study design between different studies. Studies in which the late follow-up imaging was performed mostly in symptomatic patients showed a 5-year patency rate similar to the present study. ${ }^{8}$ Although there was little difficulty in securing early postoperative coronary $\mathrm{CT}$ angiograms, obtaining later follow-up CT angiograms was more difficult, especially in asymptomatic patients and those patients with longer follow-up periods. Therefore, the coronary $\mathrm{CT}$ angiograms in the present study tended to be carried out in more symptomatic patients with a higher likelihood of showing graftrelated problems. Studies have shown the graft patency rate in symptomatic patients to be approximately $15 \%$ to $20 \%$ lower than that of asymptomatic patients. ${ }^{11}$ 
TABLE 3. Risk factor analysis for graft occlusion

\begin{tabular}{|c|c|c|c|c|}
\hline & \multicolumn{2}{|c|}{ Univariate analysis } & \multicolumn{2}{|c|}{ Multivariate analysis } \\
\hline & Hazard ratio $(\mathrm{CI})$ & $P$ value & Hazard ratio $(\mathrm{CI})$ & $P$ value \\
\hline Composite graft & $1.67(1.17-2.38)$ & .005 & $1.61(1.08-2.41)$ & .02 \\
\hline OPCAB & $1.523(1.067-2.176)$ & .021 & - & - \\
\hline Sequential anastomosis & $1.13(0.80-1.59)$ & .495 & - & - \\
\hline LVEF $(\%)$ & $1.015(0.996-1.033)$ & .117 & - & - \\
\hline Age (y) & $0.99(0.97-1.01)$ & .204 & - & 一 \\
\hline Territory & & .008 & & .005 \\
\hline LAD & & Reference & & \\
\hline $\mathrm{LCx}$ & $2.22(1.29-3.83)$ & .004 & $2.437(1.254-4.734)$ & .009 \\
\hline RCA & $2.60(1.35-5.02)$ & .004 & $3.583(1.667-7.699)$ & .001 \\
\hline Target stenosis $<90 \%$ & $1.99(1.34-2.97)$ & .001 & $2.021(1.353-3.021)$ & .001 \\
\hline
\end{tabular}

$O P C A B$, Off-pump coronary artery bypass surgery; $L V E F$, left ventricular ejection fraction; $L A D$, left anterior descending artery territory; $L C x$, left circumflex artery territory; $R C A$, right coronary artery territory; $C I$, confidence interval.

The patency rate of the non-RA grafts, that is, LITA $(\mathrm{n}=$ 872 patients, $97.6 \%)$ and SVG $(\mathrm{n}=535$ patients, $59.9 \%)$, were also analyzed. The 1-, 2-, and 5-year patency rates of LITA at $97.5 \%, 96.5 \%$, and $93.3 \%$ were superior to that of either the RA graft or the SVG at these intervals, which showed patency rates of $86.4 \%, 77.9 \%$, and $60.2 \%$, respectively. The SVG in turn showed inferior patency to that of the RA graft.

The LITA and SVG patency rates, which were lower in the present study compared with the reported results of other studies, may be attributed to the use of coronary CT angiography rather than direct coronary angiography as the imaging modality for patency assessment. The decline in patency, especially in the latter part of the follow-up, may be due to a general tendency to perform follow-up imaging studies in consenting patients and symptomatic patients, which showed an increase with each year.

According to the current study, RA bypassed to subcritically stenotic target vessels $(<90 \%)$ and composite grafting were identified as risk factors for graft failure. Direct aortic anastomosis seemed especially important for bypassing subcritically stenotic target vessels, provided the RA graft length was adequate.

The quality of MDCT imaging has advanced rapidly, with a current resolution of approximately $500 \mu \mathrm{m} .{ }^{19}$ Although selective angiography remains the gold standard, the quality of MDCT imaging has improved sufficiently for it to be comparable to selective angiography in detecting significant vascular stenosis or occlusion for the purposes of the current study. Advantages of MDCT include its noninvasive nature, its rapidity, and the need for less radiation compared with conventional angiography. ${ }^{19}$ For detection of more than $50 \%$ stenoses on a per-segment basis, the dual-source CT showed a sensitivity, specificity, positive predictive value, and negative predictive value of $88 \%, 98 \%, 78 \%$, and $99 \%$, respectively. ${ }^{20,21}$ Furthermore, because there was no selection bias in the present study between the 2 groups with regard to the follow-up coronary CT angiogram, we believe the results of the $\mathrm{CT}$ angiograms provide a valid intergroup comparison.

\section{Study Limitations}

Nonrandomization of patient selection was a major weakness of the current study. The decision for selecting the proximal RA anastomosis site was based on several factors; surely surgeon preference was a major determinant, but more important, the disease severity of the ascending aorta, graft length, and distribution of the target vessels were some of the important reasons. The discrepancy in the number of distal anastomoses between the composite group and the aorta RA group seems to be attributed to the need to maximize the number of anastomoses that can be made with the RA graft because the length gained by the LITA composite grafting may facilitate sequential anastomosis. It is conceivable that multivessel disease requiring multiple bypasses may result in a lower left ventricular ejection fraction with multiple bypass requirements. However, the relatively limited length of the RA may not be amenable to sequential bypassing by proximally anastomosing with the aorta. Therefore, composite grafting performed with sequential bypassing in mind may coincidentally have occurred with greater frequency in patients with a relatively lower ejection fraction and, subsequently, higher allocation to RA composite grafting.

The greater incidence of composite grafting in the patients undergoing $\mathrm{OPCAB}$ may be driven by a desire to perform a no-touch technique and avoid ascending aortic manipulation, especially when diseased, which in both cases would necessitate composite grafting with the LITA. For these reasons, patient selection for OPCAB and sequential anastomoses may seem biased influence on graft patency, but multivariate analysis adjusting for these and other factors did not show OPCAB and sequential bypassing to have a direct effect on the overall patency of RA grafts.

The severity of the target stenosis was derived from visual assessment and not quantitative angiography. Although 


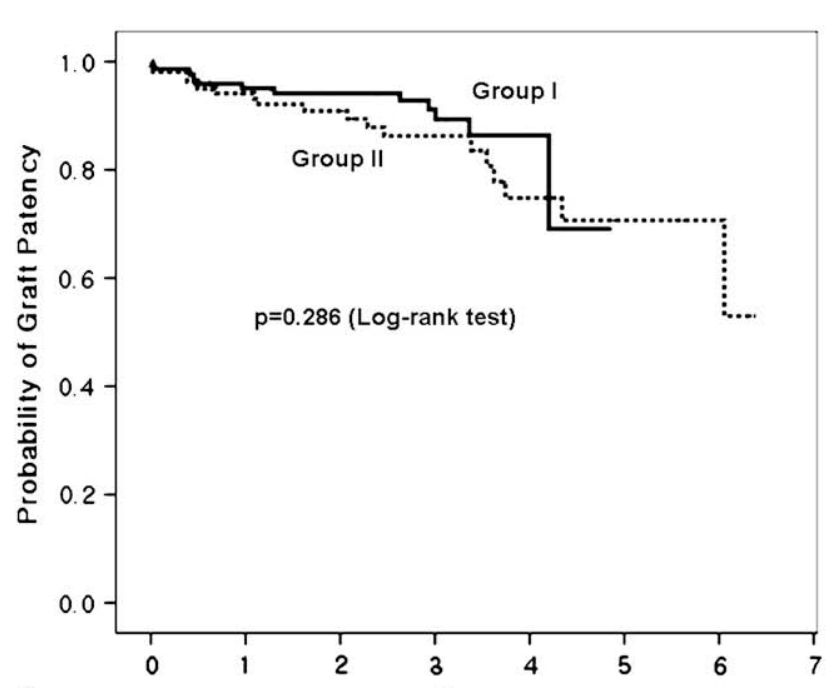

A

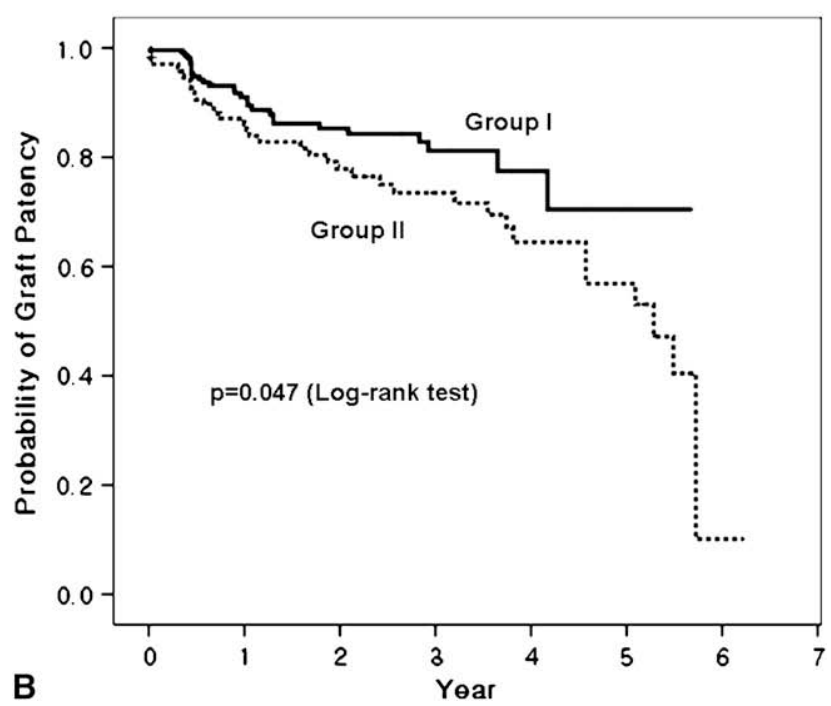

FIGURE 4. Comparisons of patency rates between groups I and II according to the target vessel stenosis. Target vessel stenosis $90 \%$ or more (A) and less than $90 \%$ (B).

using the RA graft was usually avoided in patients with endstage renal disease requiring hemo- or peritoneal dialysis, it was sometimes used in patients with non-oliguric chronic renal dysfunction. Coronary CT angiogram imaging was also frequently avoided in patients with non-oliguric chronic renal dysfunction or acute renal failure to prevent high postoperative contrast dye burden. Therefore, postoperative renal function and patient consent were prerequisites to performing postoperative coronary $\mathrm{CT}$ angiograms. Consequently, the presence of these factors limited the performance of routine follow-up CT angiograms in a large proportion of the patients who were initially identified as being potential candidates for the current study.

The patients in the earlier part of this study underwent CT analysis with 16-channel MDCT and later transitioned to 64-channel analysis with improvement in the coronary CT angiogram image quality. Although still inferior to conventional coronary angiogram, ${ }^{19}$ 16- and 64-channel CT show similar degrees of accuracy in determining graft and native coronary artery patency by our radiologists. Moreover, coronary $\mathrm{CT}$ angiogram was found to have adequate power as a diagnostic tool for evaluating graft patency status independently of the proximal anastomosis site.

\section{CONCLUSIONS}

Direct aorta to RA bypass grafting results in significantly superior early and late patency rates compared with composite grafting. Therefore, careful consideration of the potential implications for reduced graft durability before RA composite grafting seem warranted, especially when bypassing less than critically stenotic right or circumflex territories.

\section{References}

1. Loop FD, Lytle BW, Cosgrove DM, Stewart RW, Goormastic M, Williams GW, et al. Influence of the internal-mammary-artery graft on 10-year survival and other cardiac events. N Engl J Med. 1986;314:1-6.

2. Carpentier A, Guermonprez JL, Deloche A, Frechette C, DuBost C. The aortato-coronary radial artery bypass graft. A technique avoiding pathological changes in grafts. Ann Thorac Surg. 1973;16:111-21.

3. Acar C, Ramsheyi A, Pagny JY, Jebara V, Barrier P, Fabiani JN, et al. The radial artery for coronary artery bypass grafting: clinical and angiographic results at five years. J Thorac Cardiovasc Surg. 1998;116:981-9.

4. Possati G, Gaudino M, Prati F, Alessandrini F, Trani C, Glieca F, et al. Long-term results of the radial artery used for myocardial revascularization. Circulation. 2003;108:1350-4.

5. Iaco AL, Teodori G, Di Giammarco G, Di Mauro M, Storto L, Mazzei V, et al. Radial artery for myocardial revascularization: long-term clinical and angiographic results. Ann Thorac Surg. 2001;72:464-9.

6. Calafiore AM, Teodori G, Di Giammarco G, D'Annunzio E, Angelini R, Vitolla G, et al. Coronary revascularization with the radial artery: new interest for an old conduit. J Card Surg. 1995;10:140-6.

7. Mussa S, Choudhary BP, Taggart DP. Radial artery conduits for coronary artery bypass grafting: current perspective. J Thorac Cardiovasc Surg. 2005;129:250-3.

8. Maniar HS, Barner HB, Bailey MS, Prasad SM, Moon MR, Pasque MK, et al. Radial artery patency: are aortocoronary conduits superior to composite grafting? Ann Thorac Surg. 2003;76:1498-504.

9. Maniar HS, Sundt TM, Barner HB, Prasad SM, Peterson L, Absi T, et al. Effect of target stenosis and location on radial artery graft patency. $J$ Thorac Cardiovasc Surg. 2002;123:45-52.

10. Sajja LR, Mannam G, Pantula NR, Sompalli S. Role of radial artery graft in coronary artery bypass grafting. Ann Thorac Surg. 2005;79:2180-8.

11. Lytle BW, Loop FD, Thurer RL, Groves LK, Taylor PC, Cosgrove DM. Isolated left anterior descending coronary atherosclerosis: long-term comparison of internal mammary artery and venous autografts. Circulation. 1980;61: 869-74.

12. Collins P, Webb CM, Chong CF, Moat NE. Radial artery versus saphenous vein patency randomized trial: five-year angiographic follow-up. Circulation. 2008; 117:2859-64.

13. Desai ND, Cohen EA, Naylor CD, Fremes SE. A randomized comparison of radial-artery and saphenous-vein coronary bypass grafts. $N$ Engl J Med. 2004;351: 2302-9.

14. Nezic DG, Knezevic AM, Milojevic PS, Dukanovic BP, Jovic MD, Borzanovic MD, et al. The fate of the radial artery conduit in coronary artery bypass grafting surgery. Eur J Cardiothorac Surg. 2006;30:341-6.

15. Lemma M, Mangini A, Gelpi G, Innorta A, Spina A, Antona C. Is it better to use the radial artery as a composite graft? Clinical and angiographic results of aorto-coronary versus Y-graft. Eur J Cardiothorac Surg. 2004;26: 110-7.

16. Malyar NM, Gossl M, Beighley PE, Ritman EL. Relationship between arterial diameter and perfused tissue volume in myocardial microcirculation: 
a micro-CT-based analysis. Am J Physiol Heart Circ Physiol. 2004;286: H2386-92.

17. Possati G, Gaudino M, Alessandrini F, Luciani N, Glieca F, Trani C, et al. Midterm clinical and angiographic results of radial artery grafts used for myocardial revascularization. J Thorac Cardiovasc Surg. 1998;116:1015-21.

18. Shah PJ, Seevanayagam S, Rosalion A, Gordon I, Fuller J, Raman JS, et al. Patency of the radial artery graft: angiographic study in 209 symptomatic patients operated between 1995 and 2002 and review of the current literature. Heart Lung Circ. 2004;13:379-83.
19. Buxton B, Tatoulis J, Fuller J. Arterial conduits update. Heart Lung Circ. 2005; 14(Suppl 2):S14-7.

20. Scheffel H, Alkadhi H, Plass A, Vachenauer R, Desbiolles L, Gaemperli O, et al. Accuracy of dual-source CT coronary angiography: first experience in a high pretest probability population without heart rate control. Eur Radiol. 2006;16: 2739-47.

21. Johnson TR, Nikolaou K, Busch S, Leber AW, Becker A, Wintersperger BJ, et al. Diagnostic accuracy of dual-source computed tomography in the diagnosis of coronary artery disease. Invest Radiol. 2007;42:684-91.

Access to The Journal of Thoracic and Cardiovascular Surgery Online is reserved for print subscribers!

Full-text access to The Journal of Thoracic and Cardiovascular Surgery Online is available for all print subscribers. To activate your individual online subscription, please visit The Journal of Thoracic and Cardiovascular Surgery Online, point your browser to http://www.mosby.com/itcvs, follow the prompts to activate your online access, and follow the instructions. To activate your account, you will need your subscriber account number, which you can find on your mailing label (note: the number of digits in your subscriber account number varies from 6 to 10). See the example below in which the subscriber account number has been circled:

\section{Sample mailing label}

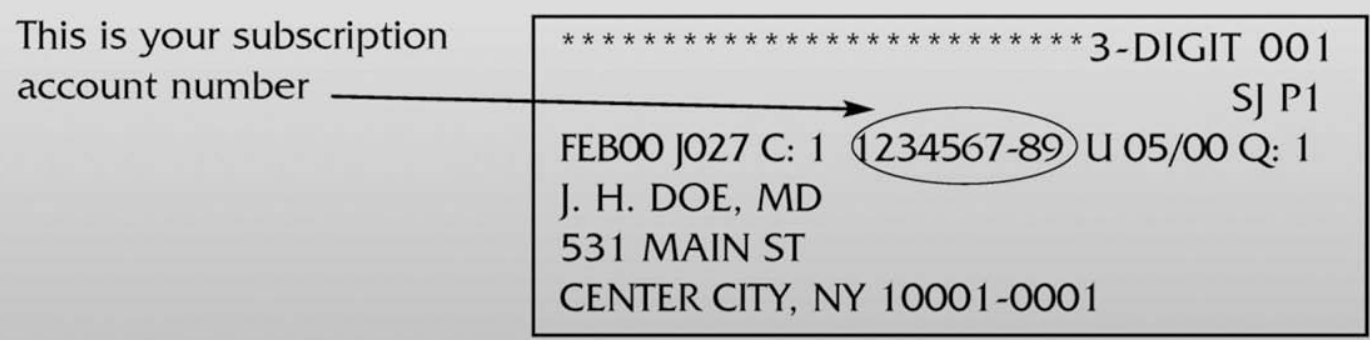

Personal subscriptions to The Journal of Thoracic and Cardiovascular Surgery Online are for individual use only and may not be transferred. Use of The Journal of Thoracic and Cardiovascular Surgery Online is subject to agreement to the terms and conditions as indicated online. 